\title{
Progress of the earthquake early warning system in Fujian, China
}

\author{
Xing Jin • Yongxiang Wei $\cdot$ Jun Li $\cdot$ \\ Hongcai Zhang $\cdot$ Qiang Ma $\cdot$ Lanchi Kang
}

Received: 22 October 2012/Accepted: 12 September 2013/Published online: 14 December 2013

(C) The Seismological Society of China, Institute of Geophysics, China Earthquake Administration and Springer-Verlag Berlin Heidelberg 2013

\begin{abstract}
In this article, we systematically introduce the latest progress of the earthquake early warning (EEW) system in Fujian, China. We focus on the following key technologies and methods: continuous earthquake location and its error evaluation; magnitude estimation; reliability judgment of EEW system information; use of doubleparameter principle in EEW system information release threshold; real-time estimation of seismic intensity and available time for target areas; seismic-monitoring network and data sharing platform; EEW system information release and receiving platform; software test platform; and test results statistical analysis. Based on strong ground motion data received in the mainshock of the Wenchuan earthquake, the EEW system developed by the above algorithm is simulated online, and the results show that the system can reduce earthquake hazards effectively. In addition, we analyzed four earthquake cases with magnitude greater than 5.5 processed by our EEW system since the online-testing that was started one year ago, and results indicate that our system can effectively reduce earthquake hazards and have high practical significance.
\end{abstract}

Keywords Earthquake early warning . Continuously earthquake location - Magnitude estimation · Double-parameter principle

X. Jin $(\bowtie) \cdot$ Y. Wei · J. Li $\cdot$ H. Zhang $\cdot$ L. Kang Earthquake Administration of Fujian Province, Fuzhou 350003, China

e-mail: wyongx@fjea.gov.cn

H. Zhang · Q. Ma

Institute of Earthquake Mechanics, China Earthquake Administration, Harbin 150006, China

\section{Introduction}

Earthquake early warning (EEW) is based on the basic principle that electronic waves travels much faster than seismic waves and destructive seismic waves (S-waves, i.e., surface waves), and spread more slowly than the firstarriving and less-destructive P-waves. Based on the realtime monitoring data observed by seismic stations that are deployed in areas of high seismic activity, we can release warning information rapidly after an earthquake occurs. People can then take some necessary measures to protect themselves, and earthquake hazards will be reduced effectively.

The concept of EEW was first proposed by Cooper (1868). With the continuous development of computers, and data transmission and seismic-monitoring technologies, many earthquake-prone countries in the world have already set up their own EEW systems within special facilities, individual cities, or even over large regions. Some of these systems have already achieved significant earthquake-hazard mitigation results. Examples of modern EEW systems include the SAS system in Mexico, put into formal operation in 1993 (Espinosa-Aranda et al. 1995; Iglesias et al. 2007; Suarez et al. 2009); the JMA EEW system in Japan, initiated in October 2007 (Kamigaichi 2004; Kamigaichi et al. 2009; Nakamura 1988; Nakamura et al. 2009); the ElarmS system in North America (Allen and Kanamori 2003; Allen et al. 2007, 2009a, b; Wurman 2007); the EEW system in Istanbul (Erdik et al. 2003); the SAOS system that provides service for Oaxaca, Mexico (Espinosa-Aranda et al. 2009); the EEW system in Bucharest, Romania (Beose et al. 2007); the EEW system in Italy (Weber et al. 2007; Zollo et al. 2004); and the EEW system in the Taiwan region (Wu et al. 1997; Wu and Teng 2002; Wu and Kanamori 2005; Hsiao et al. 2009). 
Shortly after the large Wenchuan earthquake in 2008, an earthquake with magnitude 7.2 occurred in Iwate Prefecture of Japan, and the JMA EEW system released the warning information to public $12 \mathrm{~s}$ before the arrival of the destructive seismic waves. As a result of this timely warning, casualties and property losses caused by the earthquake were reduced effectively. On March 11, 2011, just a few seconds after the $M_{\mathrm{W}} 9.0$ Tohoku earthquake occurred, people living in Tokyo received warning information $60 \mathrm{~s}$ in advance, and the whole society treated the earthquake calmly, without panic. These recent successes highlight the effectiveness of EEW systems, and indicate that these systems will play more important roles in future earthquake-hazard mitigation. Therefore, setting up an EEW system in Mainland China as soon as possible is a very meaningful work. Scholars in our country have studied the related technologies for a long time ( $\mathrm{Li}$ et al. 2004; Liao and Huang 2002; Li 2007, 2008; Ma 2008; Ni 2008; Peng et al. 2011). In 2009, a project named "Research and pilot application of EEW system and seismic intensity rapid report (SIRR) system" was funded by the Ministry of Science and Technology (MOST), and this indicates the EEW system moved to the practical development stage in Mainland China. After 3 years of research and development, our EEW system has been basically completed, and now we are doing some tests of our system in Fujian, China. Our system was designed based on the full summary of related construction experiences at home and abroad, especially the EEW system in Japan, and combining these data with the actual situation in our country, we then developed our system. The technical solution adopted in the EEW system is shown in Fig. 1, including real-time seismic and strong-motion networks, real-time seismic data-sharing platform, real-time simulation technology,

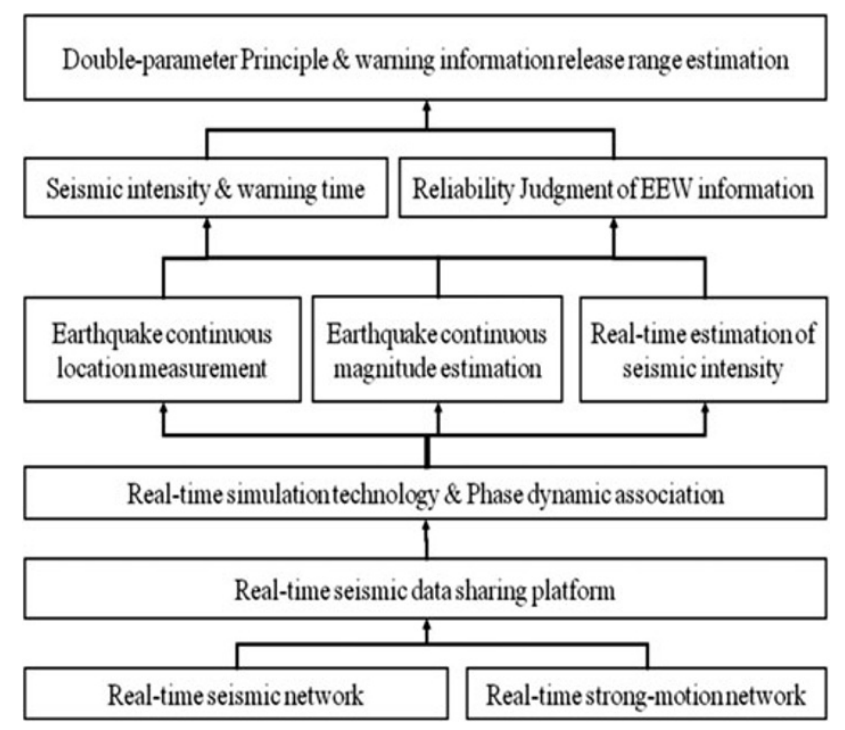

Fig. 1 The EEW System technical solution earthquake continuous location measurement, earthquake continuous magnitude estimation, real-time estimation of seismic intensity, reliability-judgment of EEW information, and double-parameter principle. In this article, we shall make a detailed introduction of the latest progress of this system, some special functions of the system, and some key issues resolved in the system.

\section{Key technologies in our EEW system}

\subsection{Monitoring network design and ability evaluation}

In order to fulfill the requirements of the EEW system and the SIRR system at the same time, we deployed both an accelerometer and a velocimeter in one station. These double-meter stations are mainly distributed in some earthquake-prone areas. As a result of this double-meter configuration, we can both monitor small and moderate earthquakes and solve the clipping problem when great earthquakes occur. Seismometry stations are mainly used to locate earthquakes in EEW system, and data from strong ground motion stations are applied to evaluate earthquake magnitude and seismic intensity when large earthquakes occur. In every county of Fujian province, we have one SIRR station at least, with each one of them being equipped with an accelerometer, and these stations were mainly used to evaluate the impact of the earthquake. Monitoring data from both kinds of stations can be mutually utilized, and the idea of "one network, multiple applications" was accomplished in this way.

By simulating the actual operating status of EEW stations, we can make an evaluation of the EEW capability in this region. The simulation contains two parts. First, we simulate the data transmission delay time $\tau$, which is the time difference corresponding to when the earthquake was detected at a station, and data transferred to the processing center, thereby achieving phase recognition. Second, we can simulate time needed to obtain certain information (earthquake location and magnitude calculation.) and release it to the public, in theory. According to our research, by just using two or three stations' P-wave arrival data, we can get a reliable location result. In order to acquire an accurate magnitude result, we need at least one station's data, which is what we have named the $2+1$ / $3+1$ scheme. By using the historical earthquake data or using a homogeneous distribution assumption of focuses, we can make an estimation of the most available time for different cities under ideal conditions. Combined with these two simulations, we can make an objective evaluation of the capability of the EEW system in detecting if all monitoring stations are at normal working conditions. According to this evaluation result, we can take some 
corresponding measures to improve the capability of the EEW system, such as increasing the number of stations, or decreasing the data transmission delay time.

\subsection{Interference elimination-phases dynamic association}

As we all know, according to the seismic wave propagation theory, P-phases generated by the same source will be perfectly correlated. In other words, by using different interrelated P-phases that are extracted from different stations, we can locate an earthquake. As the Earth medium is not as homogeneous as we thought, we can only locate the earthquake in a certain spatial region, not just a point, and this region can be expressed as a sphere with a radius of $r_{\mathrm{c}}$.

Suppose the hypocenter is located at $\left(x_{0}, y_{0}, h\right)$, the location error radius is $r_{\mathrm{c}}$, and the location of station $\mathrm{S}$ is $\left(x_{\mathrm{s}}, y_{\mathrm{s}}, 0\right)$, then focal distance of this station is as follows:

$R_{0}=\left[\left(x_{0}-x_{\mathrm{s}}\right)^{2}+\left(y_{0}-y_{\mathrm{s}}\right)^{2}+h^{2}\right]^{1 / 2}$

For any point $\left(x_{j}, y_{j}, z_{j}\right)$ in the error sphere, the distance between it and station $\mathrm{S}$ can be expressed as

$R_{j}=\left[\left(x_{j}-x_{\mathrm{s}}\right)^{2}+\left(y_{j}-y_{\mathrm{s}}\right)^{2}+z_{j}^{2}\right]^{1 / 2}$

We define

$\Delta t_{j}=\frac{\left|R_{j}-R_{0}\right|}{v_{\mathrm{p}}}$

If the real hypocenter $O_{j}$ has the uniform distribution in the error sphere, then $\Delta t_{j}$ will be a random variable. For different focal distances and depths, we can get a statistical probability distribution of $\Delta t_{j}$, and we use $\Delta t_{0.95}$ to represent the time difference $\Delta t_{j}$ when it has a probability of $95 \%$. According to our study (by using the crust velocity structure model of south China), the relation between $\Delta t_{0.95}$ and $r_{\mathrm{m}}$ are as follows:

$\Delta t_{0.95}=(-0.0007 h+0.1349) r_{\mathrm{m}}$,

where $h$ is the earthquake depth. For the special monitoring network, the control area for each station is restricted by using the Voronoi triangulation. For the first triggered station, if the maximum radium of its control area is $r_{\mathrm{m}}$, then the maximum location error will be $r_{\mathrm{m}}$; if $h=0$, then,

$\Delta t_{0.95}=0.1349 r_{\mathrm{m}}$

If other monitoring stations are successively triggered, we define

$\Delta t_{j}=\left|T_{j}^{\mathrm{e}}-T_{j}\right|$,

where $T_{j}^{\mathrm{e}}$ is the theoretical arrival time of a P-wave, and $T_{j}$ is the actual arrival time of the $\mathrm{P}$-wave. If the epicenter and origin time of the earthquake are known, then these parameters can be calculated theoreticlly.

If $\Delta t_{j} \leq \Delta t_{0.95}$, then the phase extracted from $j$ station is associated with the first station; otherwise, they do not relate. According to the locating results, we can determine the associated phases easily. By taking this phase dynamic association method, we can eliminate interference phases, and the quality of the locating result will be improved.

\subsection{Earthquake continuous location and locating error evaluation}

Compared with conventional earthquake locating methods, in the EEW system, there is very little information that can be used. In order to locate an earthquake accurately and rapidly, we start our locating procedure when just one station is triggered, and then two, three, four stations' P-wave arrival information are used continuously. During the location procedure, not just the triggered stations are used, but also those not-triggered stations are used to constrain the possible epicenter locations.

In a local coordinate system, if we set the first triggered station as the origin of the coordinates, and set the direction from the first triggered station to the second station as the $X$-axis direction, then the $Y$-axis direction can be determined by the right-hand rule. Suppose the locations of the third and fourth triggered station in this coordinate system are $\left(x_{3}, y_{3}\right)$ and $\left(x_{4}, y_{4}\right)$, respectively, and the hypocenter is located at $(x, y, h)$, then it can be calculated by using the following formula:

$\left\{\begin{array}{l}x=p_{1}+p_{2} r_{1} \\ y=b_{1}+b_{2} r_{1}\end{array}\right.$,

where

$\left\{\begin{array}{l}p_{1}=\frac{1}{2 d_{12}}\left(d_{12}^{2}-S_{21}^{2}\right) \\ p_{2}=-\frac{S_{21}}{d_{12}} \\ b_{1}=\frac{1}{2 y_{3}}\left(d_{13}^{2}-2 x_{3} p_{1}-S_{31}^{2}\right) \\ b_{2}=-\frac{1}{y_{3}}\left(x_{3} p_{2}+S_{31}\right)\end{array}\right.$

And

$\left\{\begin{array}{l}S_{21}=r_{2}-r_{1}=V_{\mathrm{p}}\left(T_{\mathrm{p} 2}-T_{\mathrm{p} 1}\right)=V_{\mathrm{p}} t_{21} \\ S_{31}=r_{3}-r_{1}=V_{\mathrm{p}}\left(T_{\mathrm{p} 3}-T_{\mathrm{p} 1}\right)=V_{\mathrm{p}} t_{31} \\ S_{41}=r_{4}-r_{1}=V_{\mathrm{p}}\left(T_{\mathrm{p} 4}-T_{\mathrm{p} 1}\right)=V_{\mathrm{p}} t_{41}\end{array}\right.$

When just one station is triggered, the possible epicenter is constrained to the control area of the station divided by the Voronoi split, and with the increase of time, the 
possible area is gradually reduced. When the second station is triggered, the epicenter is constrained to a set of hyperbolas each of which represents a focal depth. When the third station is triggered, the possible epicenter will be located in a limited linear path determined by the above equations, and each node in the lines has different focal depths. When the fourth station is triggered, or we recognized the S-wave phase of the first station, the epicenter can be calculated accurately by using the location formula. Further, the detailed process of earthquake continuous location is discussed in another article (Zhang et al. 2011).

\subsection{Earthquake magnitude estimation}

There are several kinds of earthquake magnitude estimation methods used in the world, and after careful comparison and research, we found it is very hard to get an accurate magnitude estimation result when we just use the few several seconds' seismic waves. First, a good EEW magnitude estimation method should be able to calculate the magnitude real time and correct the result continuously. Second, for big earthquakes, the near-field records will have the problem of body wave magnitude saturation; therefore, we must develop a new magnitude scale to solve the problem. The most effective method is the intensity magnitude $M_{\mathrm{I}}$ (Hourichi). In summary, we take two methods to calculate earthquake magnitude:

(1) Peak ground displacement method:

$M=a_{1}(t) \log _{10} U_{\max }(t)+a_{2}(t) \log _{10}\left(\Delta+\Delta_{0}\right)+a_{3}(t)$,

where $a_{1}(t), a_{2}(t)$, and $a_{3}(t)$ are coefficients in $t$ seconds since P-wave arrival; and $U_{\max }(t)$ is Peak ground displacement in $t$ seconds since $\mathrm{P}$-wave arrival. The values of coefficients are listed in Table 1.

(2) Intensity magnitude method:

After a station is triggered, instrumental intensity of the station can be calculated in real time as the monitoring data real-time transmission. Then, we use the following equation to estimate the intensity magnitude:

$\left\{\begin{array}{l}I_{0}=b_{1}+b_{2} I+b_{3} \log _{10}\left(\Delta+\Delta_{0}\right) \\ M=c_{1}+c_{2} I_{0}\end{array}\right.$,

where $I_{0}$ is the epicentral intensity, $\Delta$ is epicentral distance, $\Delta_{0}$ is a constant value, and $b_{1}, b_{2}, b_{3}, c_{1}$, and $c_{2}$ are coefficients in the intensity attenuation formula; here, $b_{1}=$ $-2.72, b_{2}=1.00, b_{3}=2.72, c_{1}=2.45$, and $c_{2}=0.51$.

If several stations are available, each station will have a different weighting factor according to its signal-to-noise ratio.
Table 1 Values of Coefficients for formula 10

\begin{tabular}{llll}
\hline$t(\mathrm{~s})$ & $a_{1}$ & $a_{2}$ & $a_{3}$ \\
\hline 1 & 0.956 & 1.392 & 1.977 \\
2 & 0.946 & 1.606 & 1.542 \\
3 & 0.893 & 1.967 & 0.946 \\
4 & 0.869 & 2.114 & 0.592 \\
5 & 0.935 & 2.128 & 0.287 \\
6 & 0.987 & 1.949 & 0.309 \\
7 & 1.011 & 1.732 & 0.482 \\
8 & 1.050 & 1.537 & 0.611 \\
9 & 1.035 & 1.402 & 0.796 \\
10 & 1.016 & 1.295 & 0.964 \\
11 & 1.011 & 1.253 & 1.026 \\
12 & 1.007 & 1.230 & 1.062 \\
13 & 1.004 & 1.215 & 1.087 \\
14 & 1.002 & 1.208 & 1.098 \\
15 & 1.001 & 1.200 & 1.109 \\
16 & 1.000 & 1.195 & 1.118 \\
17 & 0.998 & 1.191 & 1.127 \\
18 & 0.997 & 1.187 & 1.133 \\
19 & 0.995 & 1.185 & 1.139 \\
20 & 0.995 & 1.184 & 1.140 \\
\hline
\end{tabular}

Both these kinds of magnitude are estimated simultaneously to evaluate earthquake magnitude. If the magnitude obtained by peak ground displacement method is $<6.0$, then the integrated magnitude is equal to it. Otherwise, the integrated magnitude is the maximum value of these two magnitudes.

\subsection{Reliability judgment of EEW information}

We used the following methods to determine the reliability of the EEW information: first of all, we judged whether the waveform data that are used in the calculations are reliable; second, we make a judgment of whether the location result is reasonable and reliable; finally, according to the magnitude and the intensity estimation result, we also make a judgment on whether the earthquake is destructive.

In our system, warning information will be released to public only after the reliability judgment of EEW information is processed.

\subsection{Warning information release-range estimation}

The information release-range depends on two important factors. One is estimation of the fault rupture scope. Speaking in general, greater magnitude means there is longer fault rupture, fault rupture has the most destructive power, and cities around the fault will suffer the most 
serious earthquake damage. Rupture length can be estimated by using the empirical equation $L=f_{1}(M)=a_{1}$ $\log _{10} M+b_{1}$. Another factor that affects the release-range is the estimation of vibration damage area. As is known, if seismic intensity exceeds VI (Chinese intensity), then people will feel strong ground motion and casualties may be recorded, which may not be the case if seismic intensity is lower than VI. By taking the seismic intensity attenuation formula $I=f_{2}(M, R)=a_{2} M+b_{2} \log _{10} R+c_{2}$, or $I=f_{3}\left(I_{0}, R\right)=a_{3} I_{0}+b_{3} \log _{10} R+c_{3}$, with a radius of VI, range can be estimated:

$R_{\mathrm{VI}}=\left.f_{2}^{\prime}(M)\right|_{I=6}=\left.f_{3}^{\prime}\left(I_{0}\right)\right|_{I=6}$

Then, the EEW information release-range is $r=$ $\max \left\{L, R_{\mathrm{VI}}\right\}$, where $a_{1}, b_{1}, a_{2}, b_{2}, c_{2}, a_{3}, b_{3}$, and $c_{3}$ are coefficients, and $I_{0}$ is epicenter seismic intensity.

\subsection{Real-time estimation of seismic intensity} and available time

EEW information is obtained mainly from P-waves; therefore, the direction of the rupture fault cannot be estimated accurately. For the sake of simplicity, we take the seismic intensity attenuation relationships $I=$ $f_{2}(M, R)=f_{3}\left(I_{0}, R\right)$ to estimate the maximum possible intensity in target areas. If earthquake-locating results are known, then distance $R$ can be calculated, and seismic intensity of the target area can be estimated by using the above formula. For earthquakes that occur inside the monitoring net, epicentral intensity, $I_{0}$ was chosen to estimate the intensity, and for earthquakes that occur outside the monitoring net, earthquake magnitude $M$ was chosen.

\subsection{Information release scheme-double-parameter principle}

According to the design idea of new monitoring networks, magnitude and epicentral intensity are the two separate parameters that we used to define different information release levels. Based on different social impacts and degrees of damage due to the earthquake, we define three levels:

(1) Emergency level: $M \geq 4.0$ and $I_{\mathrm{m}} \geq \mathrm{IV}$ Contingency plan starts and earthquake department enters state of emergency.

(2) Engineering level: $M \geq 5.0$ and $I_{\mathrm{m}} \geq \mathrm{V}$

Warning information is released to specific users, such as high-speed rails and subways.

(3) Public level: $M \geq 5.5$ and $I_{\mathrm{m}} \geq \mathrm{VI}$

Warning information will be released to public.
2.9 Test of the EEW system

After the preliminary development of the EEW system is completed, we need to do a comprehensive test on it. Our test contains two parts, in the first part, we collect several earthquake events and convert those into virtual data stream, and then the EEW system can deal with the monitoring data as if it is real time. We make analyses of the processing results, and performance of the EEW system can be evaluated effectively. The other part of test is to test the network transmission time delay of the EEW system's seismic network that will be installed for the project, i.e., to test the time delay of recorded digital signal of each station from the data collector to the time of data decoded at the server in the seismic-monitoring center. Because of the differences between the data collectors and transmission networks of the new and the old seismic stations, the time delays must be different, and the spatial distribution of time delays can be obtained.

Through the above capacity assessment, the actual ability of the EEW system can be evaluated before formal online operation.

\section{Operation of the EEW system-the Wenchuan earthquake as an example}

In order to demonstrate the operation of the EEW system, we take the large Wenchuan earthquake $M_{\mathrm{S}} 8.0$ that occurred in May 12, 2008 as an example to demonstrate the whole processing procedure. Because the ground motion in most near-field velocimeter stations was out of dynamic range, in our research, strong ground motion data provided by IEM was used. Due to the dial-up transmission mode, time scales of the records were inaccurate; therefore, we make correction of the time scale according to the nearby velocimeter stations and then convert them into virtual data stream. After this pretreatment, once monitoring data were available, the EEW system started processing. Stations that are used in this study are shown in Fig. 2, processing results shown in Table 2, and processing interface is shown in Fig. 3.

As shown in Fig. 2 and Table 2, just $4.4 \mathrm{~s}$ after the first station was triggered, earthquake location and magnitude estimation were completed. The epicentral intensity was forecast to be VIII, and there were 7-s advance notice available for Chengdu city and more than $54 \mathrm{~s}$ for Qingchuan city. Earthquake magnitude is underestimated as a result of minimal information available at this moment. By time elapsing, the EEW system revised the information gradually. When the final report was released (13.4 $\mathrm{s}$ after the first station triggered), the earthquake 


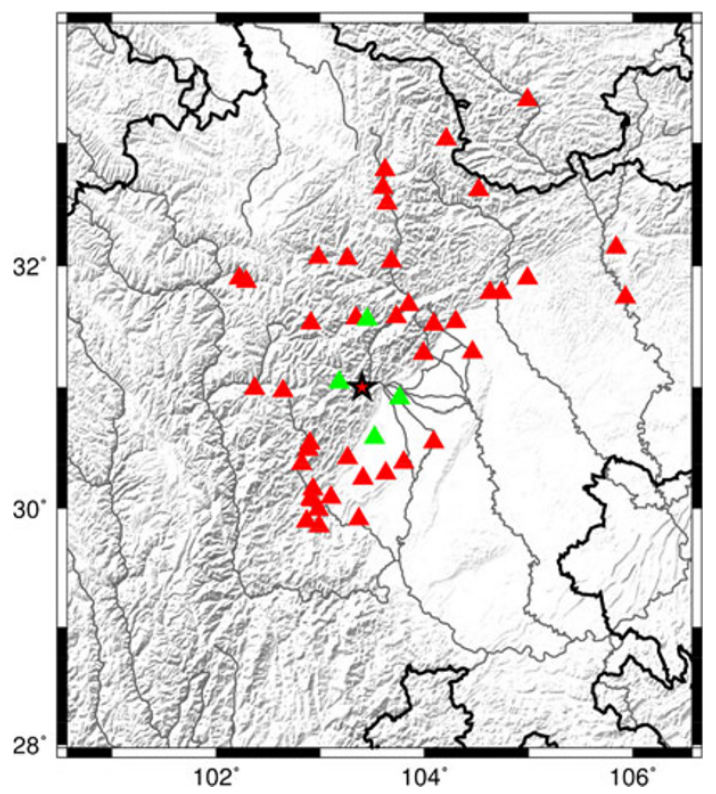

Fig. 2 Stations used in the research (Solid triangles represent stations and green solid triangles represent the nearest stations from the epicenter)

magnitude estimation and the seismic intensity results were observed to be very close to the actual results, and from these testing results, we found that it is possible to get an accurate magnitude estimation that just uses a tens of seconds' seismic waves. Although little advance notice was available for Chengdu city, there were still a few seconds that could be used for people living in Beichuan, Qingchuan, and other nearby cities. If proper measures were taken during this period, then casualties and property losses would have been reduced dramatically.

As shown in Fig. 3, in the upper left of the processing interface, red circle stands for the wave front of $S$ wave, blue circle shows the wave front of $\mathrm{P}$ wave, while black circle represents areas where forecast seismic intensity is VI. Warning target areas are indicated by small boxes, and the degree of forecast intensity is presented by color degree. In the middle of Fig. 3, a table is used to show different target areas' situations, including forecast seismic intensity and available warning times for each city. In the top right of this figure, seismic stations' waveforms are displayed real time. And the middle of the figure concludes the actually measured earthquake parameters of the first four stations, involving seismic intensity, PGA, PGV, and PGD. On the other hand, the figure at the bottom contains the released earthquake warning parameters for each warning: origin time of earthquake, epicenter longitude, latitude, focal depth, magnitude, epicentral seismic intensity, rupture length, semi-diameters of felt and damaged regions, etc.

\section{Real-time EEW system in Fujian region}

Fujian seismic-monitoring network contains 125 seismic stations as at the end of year 2012, and the distributions of seismic stations are shown in Fig. 4. Among these stations, 31 of them are equipped with velocimeters, 40 of them with accelerometers, and 54 stations are equipped with both velocimeters and accelerometers. The average separation space between two stations is about $30 \mathrm{~km}$. It can be seen from Fig. 4 that eastern coastal parts of Fujian province have intensive seismic stations, while western part is sparse. All waveform data are transferred to data-processing center located in Fuzhou in real time through private lines. Besides, sampling rate of each station is $100 \mathrm{sps}$, and each data package takes one second in common data form MiniSeed.

In addition, seismic-monitoring data of eight different stations are exchanged between Fujian region and Taiwan in real time, and the station distribution is presented in Fig. 4 too. Specifically, monitoring data are exchanged in real time through public network with the form of MiniSeed. Data length in each package is around $5 \mathrm{~s}$ with a transfer delay of about $3 \mathrm{~s}$ under the normal situation. Sampling rate of each station is $100 \mathrm{sps}$, and both are equipped with velocimeter and accelerometer.

Based on these stations, one set of automatic software for EEW system in real time was developed in 2009, which started online test running since January 2012 in Fujian.

Table 2 Simulation results of Wenchuan earthquake

\begin{tabular}{|c|c|c|c|c|c|c|c|c|}
\hline \multirow[t]{2}{*}{ Reports } & \multirow[t]{2}{*}{ Epicenter } & \multirow[t]{2}{*}{ Magnitude } & \multirow{2}{*}{$\begin{array}{l}\text { Maximum } \\
\text { intensity }\end{array}$} & \multirow{2}{*}{$\begin{array}{l}\text { Time since first } \\
\text { station triggered (s) }\end{array}$} & \multicolumn{4}{|c|}{ Available times (s) } \\
\hline & & & & & Chengdu & Beichuan & Mianyang & Qingchuan \\
\hline First & $103.40^{\circ} \mathrm{E}, 31.03^{\circ} \mathrm{N}$ & 6.1 & 8 & 4.4 & 8 & 26 & 24 & 56 \\
\hline Second & $103.40^{\circ} \mathrm{E}, 31.03^{\circ} \mathrm{N}$ & 6.2 & 8 & 7.4 & 5 & 23 & 21 & 53 \\
\hline Third & $103.39^{\circ} \mathrm{E}, 30.96^{\circ} \mathrm{N}$ & 6.7 & 10 & 8.4 & 4 & 22 & 20 & 52 \\
\hline Fourth & $103.37^{\circ} \mathrm{E}, 30.96^{\circ} \mathrm{N}$ & 6.9 & 11 & 9.4 & 3 & 21 & 19 & 51 \\
\hline Fifth & $103.37^{\circ} \mathrm{E}, 30.97^{\circ} \mathrm{N}$ & 7.4 & 11 & 11.4 & 1 & 19 & 17 & 49 \\
\hline Final & $103.37^{\circ} \mathrm{E}, 30.97^{\circ} \mathrm{N}$ & 8.3 & 11 & 13.4 & 0 & 17 & 15 & 47 \\
\hline
\end{tabular}






Fig. 3 Processing interface of EEW system software

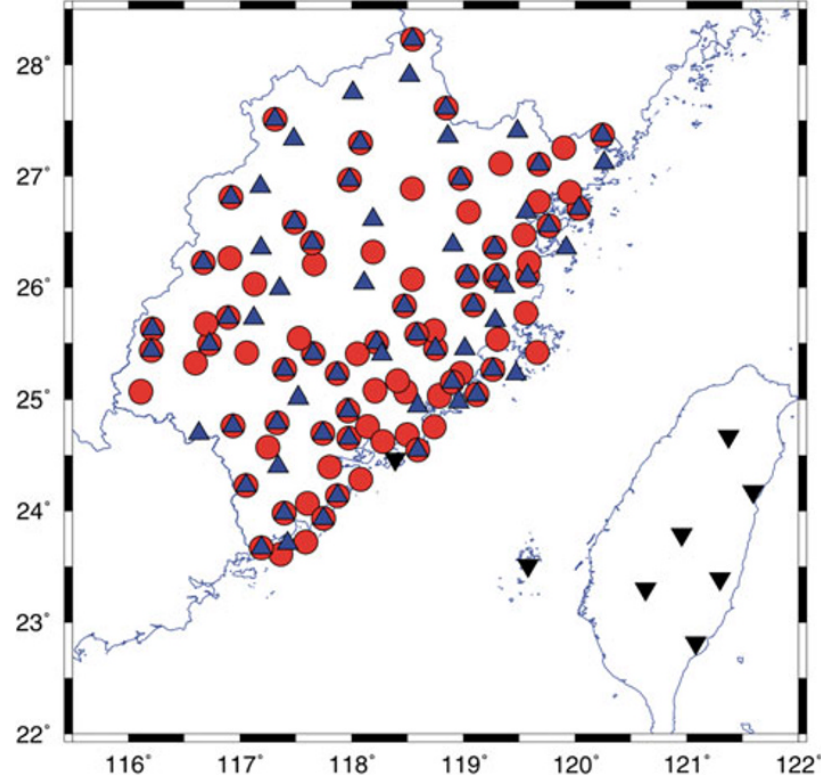

Fig. 4 Fujian seismic-monitoring network distribution (Red solid circles represent stations equipped with accelerometer, blue solid triangles represent stations equipped with seismometer, black inverted solid triangles represent Taiwan stations.)

The main purpose is to monitor felt earthquakes that occurred in both Fujian and Taiwan and try to provide earthquake warning information for different cities in
Fujian province at the same time. During the running period of one year and a half until June 2013, four earthquake events with magnitude greater than 5.5 were processed by our system. Namely, the $M_{\mathrm{S}} 5.9$ earthquake that occurred in Yilan, Taiwan on June 10, 2012; the $M_{\mathrm{S}} 5.7$ earthquake in Hualian county, Taiwan on March 7, 2013; the $M_{\mathrm{S}} 6.5$ earthquake in Nantou county, Taiwan on March 27, 2013; and the $M_{\mathrm{S}} 6.7$ earthquake in Nantou county, Taiwan on June 2, 2013 (earthquake catalog of China Earthquake Networks Center). Our system has operated immediate processing on those four earthquakes mentioned above and realized EEW. Detailed processing results are shown in Table 3.

Posted interface screenshot of the $M_{\mathrm{S}} 5.9$ earthquake that occurred in Yilan, Taiwan on June 10, 2012 and released by our EEW system is shown in Fig. 5, while information of each warning is presented in Table 2. According to the results, there were three warnings released by our online system. Precisely, $15.6 \mathrm{~s}$ after triggering the first station, the first warning was released with a magnitude estimation of 5.1, and the forecast epicentral seismic intensity was V. Only three seismic stations were triggered at that time, and $\mathrm{S}$ wave would reach Pingtan city $41 \mathrm{~s}$ later. Subsequently, the second and the third warning information were released 17.6 and $27.6 \mathrm{~s}$, respectively, after triggering of the first station. Error of earthquake location was 16.5 and $32.3 \mathrm{~km}$, 
Table 3 Results of real-time EEWS analysis for hypocenter parameters for four $M_{\mathrm{S}}>5.5$ earthquakes

\begin{tabular}{|c|c|c|c|c|c|c|c|c|c|}
\hline $\begin{array}{l}\text { Report } \\
\text { number }\end{array}$ & $\begin{array}{l}\text { Report } \\
\text { time }(s)\end{array}$ & $\begin{array}{l}\text { Latitude } \\
\left({ }^{\circ} \mathrm{N}\right)\end{array}$ & $\begin{array}{l}\text { Longitude } \\
\left({ }^{\circ} \mathrm{E}\right)\end{array}$ & $\begin{array}{l}\text { Depth } \\
(\mathrm{km})\end{array}$ & Magnitude & $\begin{array}{l}\text { Epicenter } \\
\text { intensity }\end{array}$ & $\begin{array}{l}\text { Number of } \\
\text { stations }\end{array}$ & $\begin{array}{l}\text { Epicenter } \\
\text { deviation } \\
(\mathrm{km})\end{array}$ & $\begin{array}{l}\text { Magnitude } \\
\text { deviation }\end{array}$ \\
\hline \multicolumn{10}{|c|}{ 1. Off the coast of Taiwan's Yilan 10 October $2012\left(24.5^{\circ} \mathrm{N}, 122.3^{\circ} \mathrm{E}, 50 \mathrm{~km}, M_{\mathrm{S}} 5.9\right)$} \\
\hline 1 & 15.6 & 24.34 & 121.51 & 0 & 5.1 & 5 & 3 & 89.5 & -0.8 \\
\hline 2 & 17.6 & 24.39 & 122.40 & 15 & 5.6 & 5 & 4 & 16.5 & -0.3 \\
\hline 3 & 27.6 & 24.42 & 122.58 & 32 & 6.7 & 9 & 6 & 32.3 & 0.8 \\
\hline \multicolumn{10}{|c|}{ 2. Hualien, Taiwan 7 March $2013\left(24.3^{\circ} \mathrm{N}, 121.5^{\circ} \mathrm{E}, 6 \mathrm{~km}, M_{\mathrm{S}} 5.7\right)$} \\
\hline 1 & 11.8 & 24.27 & 121.42 & 0 & 5.3 & 6 & 3 & 9.5 & -0.4 \\
\hline 2 & 17.8 & 24.28 & 121.41 & 10 & 5.5 & 6 & 4 & 10.2 & -0.2 \\
\hline 3 & 28.8 & 24.39 & 121.59 & 30 & 5.5 & 6 & 5 & 14.1 & -0.2 \\
\hline 4 & 37.8 & 24.32 & 121.65 & 30 & 5.5 & 7 & 8 & 16.8 & -0.2 \\
\hline 5 & 40.8 & 24.28 & 121.43 & 3 & 5.5 & 6 & 10 & 8.1 & -0.2 \\
\hline \multicolumn{10}{|c|}{ 3. Nantou, Taiwan 27 March $2013\left(24.0^{\circ} \mathrm{N}, 121.0^{\circ} \mathrm{E}, 8 \mathrm{~km}, M_{\mathrm{S}} 6.5\right)$} \\
\hline 1 & 17.2 & 23.92 & 121.09 & 0 & 6.5 & 10 & 3 & 13.4 & 0 \\
\hline 2 & 23.2 & 23.91 & 121.05 & 15 & 6.2 & 9 & 5 & 11.4 & -0.3 \\
\hline 3 & 33.2 & 23.91 & 121.06 & 13 & 5.8 & 8 & 9 & 12.0 & -0.7 \\
\hline 4 & 41.2 & 23.91 & 121.06 & 13 & 5.6 & 7 & 10 & 12.0 & -0.9 \\
\hline 5 & 42.2 & 23.91 & 121.06 & 13 & 5.6 & 7 & 10 & 12.0 & -0.9 \\
\hline \multicolumn{10}{|c|}{ 4. Nantou,Taiwan 2 June $2013\left(23.9^{\circ} \mathrm{N}, 120.9^{\circ} \mathrm{E}, 9 \mathrm{~km}, M_{\mathrm{S}} 6.7\right)$} \\
\hline 1 & 15.8 & 23.88 & 121.02 & 0 & 6.9 & 11 & 3 & 13.5 & 0.2 \\
\hline 2 & 21.8 & 23.89 & 121.00 & 10 & 6.2 & 9 & 5 & 11.2 & -0.5 \\
\hline 3 & 22.8 & 23.89 & 121.00 & 10 & 6.2 & 9 & 6 & 11.2 & -0.5 \\
\hline 4 & 30.8 & 23.89 & 121.00 & 10 & 5.8 & 8 & 8 & 11.2 & -0.9 \\
\hline 5 & 32.8 & 23.88 & 121.00 & 8 & 6.4 & 9 & 10 & 11.3 & -0.3 \\
\hline
\end{tabular}

respectively, with the number of triggering stations were 4 and 6, respectively. But for the first warning, epicenter deviation is $89.5 \mathrm{~km}$ which is relatively big. The main reason for this is that only three stations were triggered and used to locate the earthquake, while the deviation lessened quickly with more stations triggered.

As shown in Fig. 5, black circles in the middle part stand for regions where forecast intensity is VI, while blue circles represent regions where forecast intensity is III. Red circle presents the wave front of $\mathrm{S}$ wave, and regions in dark red represent the blind-zone. Circle dots in red show those triggering stations, while circle dots in blue are those stations with real-time data. Gray circles indicate distribution circles of warning time. Earthquake warning targets are presented by small boxes, and forecast intensity grades are presented by color grades. Table 2 in the middle right shows the details of each warning, including time from the first station triggered, epicentral seismic intensity, warning grades, etc. And another table in the lower right corner shows our warning release standards in terms of magnitude and epicenter intensity for each warning.

Posted interface screenshot of $M_{\mathrm{S}} 5.7$ earthquake occurred in Hualian county, Taiwan on March 7, 2013 as released by earthquake warning system is shown in Fig. 6, and information of each warning is presented in Table 2. It can be seen from the results that five warnings were released for this earthquake. Specifically, earthquake location and magnitude estimation were completed within $11.8 \mathrm{~s}$, once triggering the first station and then the first warning published. Although only three seismic stations were triggered, the magnitude was estimated to be 5.3, and the epicentral seismic intensity was estimated to be VI. When this warning is released, Pingtan city will get the information $45 \mathrm{~s}$ in advance before they feel the ground motion. Subsequently, the second and the fifth warning information were released by our system after 17.8 and $40.8 \mathrm{~s}$, respectively, after triggering the first station. Errors of earthquake location were 10.2 and $8.1 \mathrm{~km}$, respectively, while the numbers of triggering stations were 4 and 6 , respectively.

Posted interface screenshot of $M_{\mathrm{S}} 6.5$ earthquake occurred in Nantou County, Taiwan on March 27, 2013 as released by earthquake warning system is shown in Fig. 7, and information of each warning is presented in Table 2. Results show that there were five warnings released by our online system. Specifically, three seismic stations were triggered within 17.2 s once triggering the first station, and earthquake location and magnitude estimation of the first 


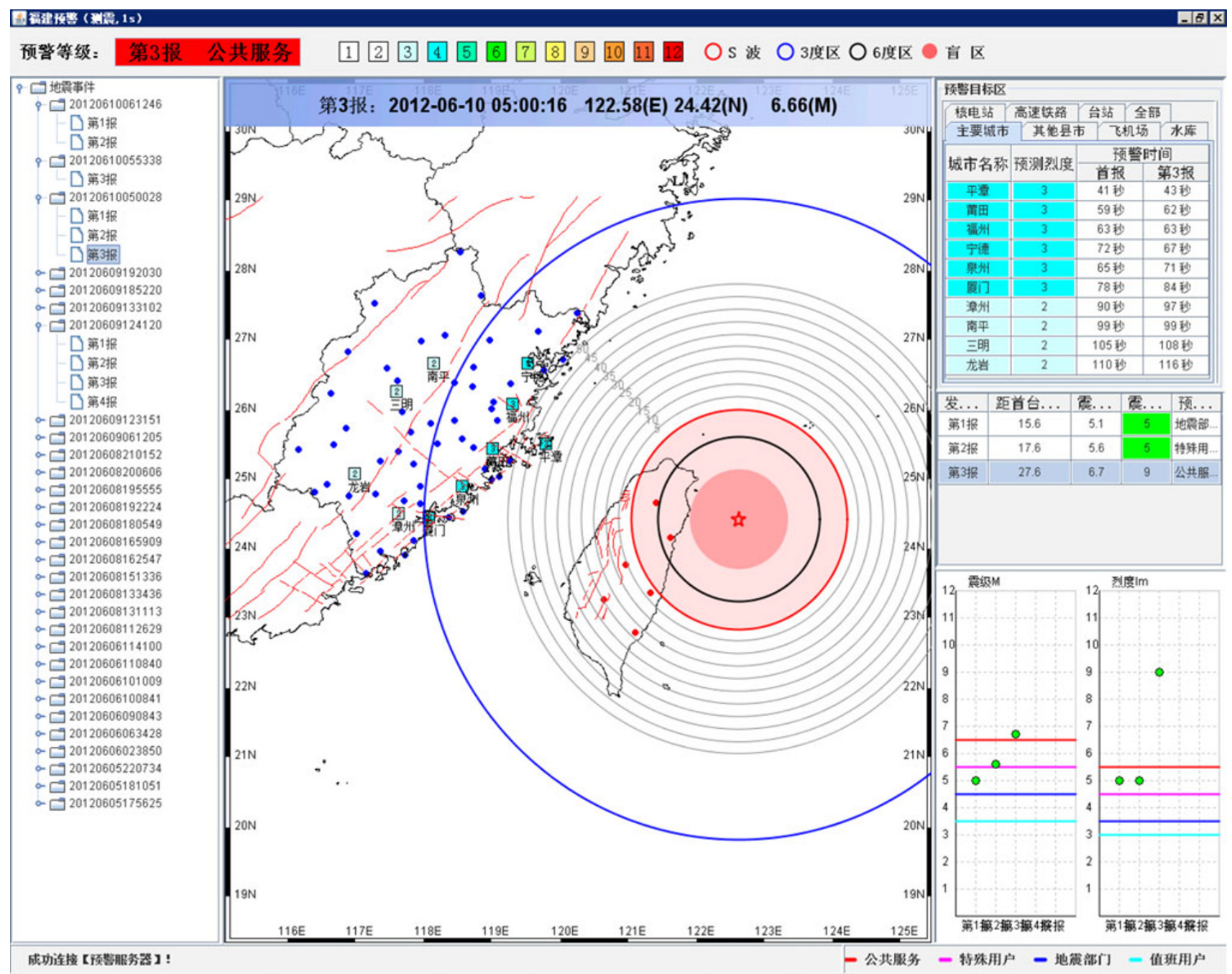

Fig. 5 Posted interface screenshot of $M_{\mathrm{S}} 5.9$ earthquake occurred in off Yilan, Taiwan (the third warning)

warning were completed within that time. The earthquake magnitude was estimated to be 6.5 , and the forecast epicentral seismic intensity was IX. And, S-wave will arrive in Pingtan city $40 \mathrm{~s}$ later, from the time this warning information was released. Subsequently, the second and the fifth warning information were released by our system after 23.2 and $43.2 \mathrm{~s}$, respectively, after triggering the first station. Error of earthquake location was 11.4 and $12 \mathrm{~km}$, respectively, with the number of triggering stations were 5 and 10 , respectively.

Posted interface screenshot of $M_{\mathrm{S}} 6.7$ earthquake occurred in Nantou county, Taiwan on June 2, 2013 as released by our system is shown in Fig. 8, and details of each warning are presented in Table 2. There were five warning information released by the earthquake warning system online, according to the results. Precisely, just $15.8 \mathrm{~s}$ after the first station triggered, the first warning was published with accurate earthquake location and earthquake magnitude estimation results. Only three stations were triggered at that moment, but we made estimation that the magnitude would be 6.9 and that the epicentral seismic intensity would be XI. And this provided 42-s warning time for Pingtan city, with a forecast seismic intensity of IV. Subsequently, the second and the fifth warning information were released by the earthquake warning system after 21.8 and $32.8 \mathrm{~s}$, respectively, after triggering the first station. Errors of earthquake locations were 11.2 and $11.3 \mathrm{~km}$, respectively, with the number of triggering stations were 5 and 10 , respectively.

\section{Discussion and conclusions}

Latest progress of the EEW system, sponsored by MOST, was introduced in this article. We gave a brief introduction of each function modules of the whole system. Using the large Wenchuan earthquake as an example, operations of 


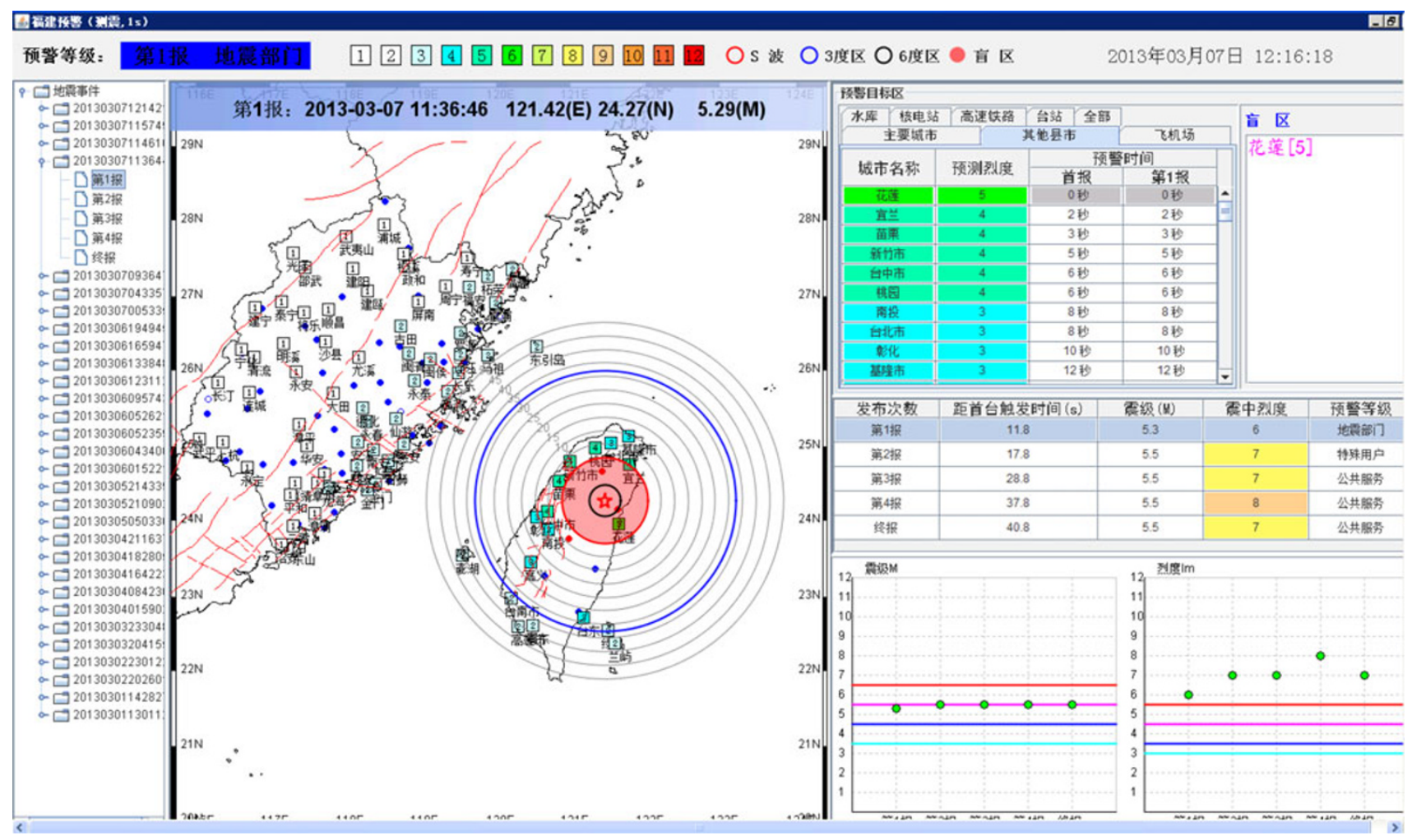

Fig. 6 Posted interface screenshot of $M_{\mathrm{S}} 5.7$ earthquake occurred in Hualian Taiwan (the first warning), legends are the same as Fig. 5



Fig. 7 Posted interface screenshot of $M_{\mathrm{S}} 6.5$ earthquake occurred in Nantou Taiwan (the first warning), legends are the same as Fig. 5 
预警等级： 终报 公共服务

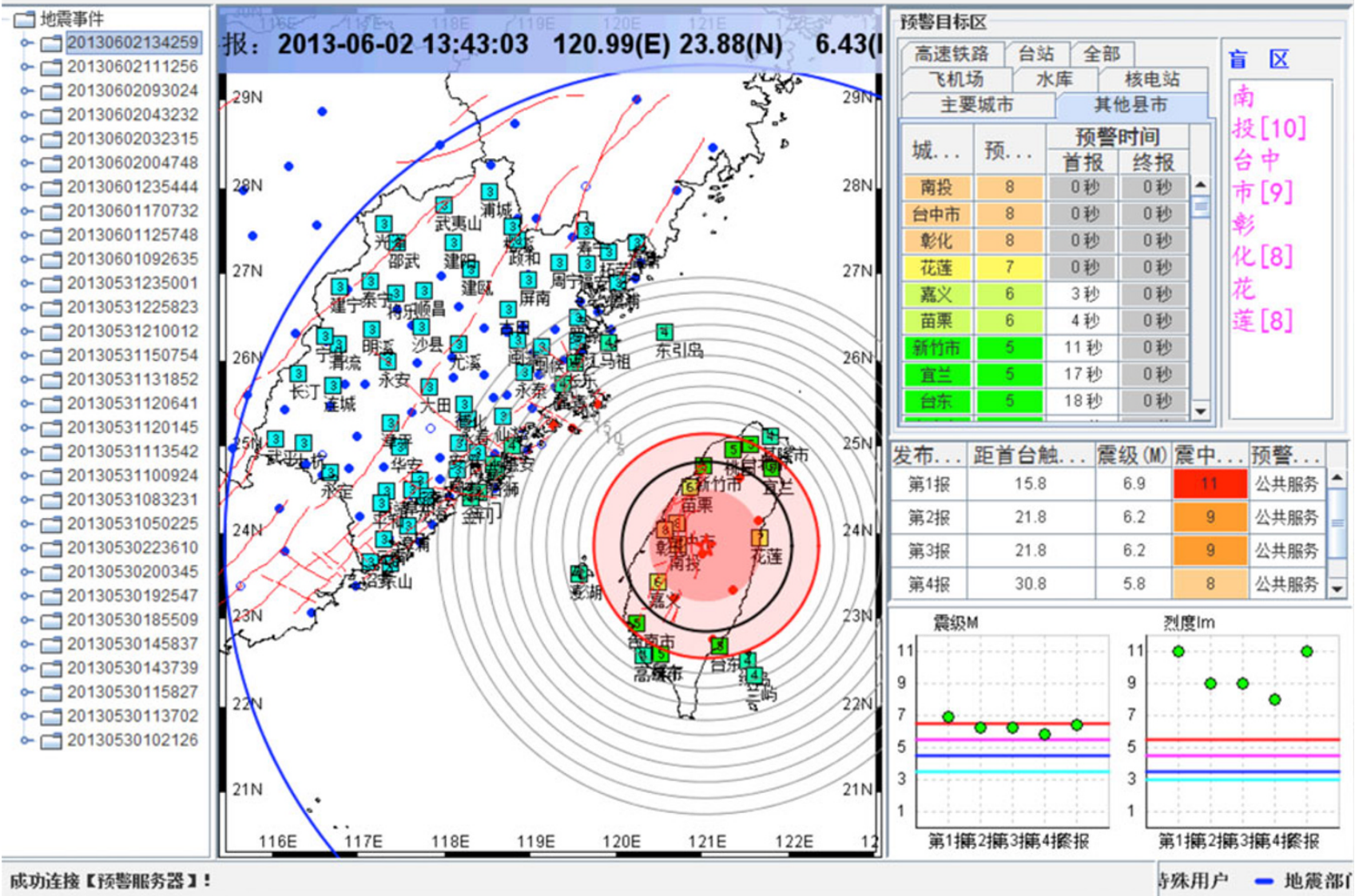

Fig. 8 Posted interface screenshot of $M_{\mathrm{S}} 6.7$ earthquake occurred in Nantou Taiwan (the fifth warning), legends are the same as Fig. 5

the system were demonstrated. The whole system is performing an online test in the Fujian region, and four $M_{\mathrm{S}}>5.5$ earthquakes have been processed by this system, indicating its capability to process earthquake warning online with a fewer deviations for processing earthquakes that happened within network, while improvements should be made to process earthquake that happened outside of monitoring network, but we will perform more simulating tests and real-time running to examine the stability and reliability of the whole system.

Acknowledgments This research is funded by the Ministry of Science and Technology (2009BAK55B02, 2009BAK55B01). The authors wish to offer many thanks to the Institute of Engineering Mechanics of China Earthquake Administration for the provision of Wenchuan earthquake strong ground motion data for this research.

\section{References}

Allen RM, Kanamori H (2003) The potential for earthquake early warning in southern California. Science 300:786-789
Allen RM, Brown H, Hellweg M, Kireev A, Neuhauser D (2007) Real-time test of the ElarmS earthquake early warning methodology. J Geophys Res 112:B08311

Allen RM, Brown H, Hellweg M, Khainovski O, Lombard P, Neuhauser D (2009a) Real-time earthquake detection and hazard assessment by ElarmS across California. Geophys Res Lett 36:L00B08

Allen RM, Gasparini P, Kamigaichi O, Beose M (2009b) The status of earthquake early warning around the world: an introductory overview. Seismol Res Lett 80(5):682-693

Beose M, Wenzel F, Erdik M, Marmureanu G (2007) Earthquake early warning for Bucharest and Istanbul. In: International symposium on strong Vrancea earthquakes and risk mitigation, Bucharest

Cooper JD (1868) Letter to editor. San Francisco Daily Evening Bulletin, 3 Nov 1868

Erdik M, Fahjan Y, Ozel O, Alcik H, Mert A, Gul M (2003) Istanbul earthquake rapid response and the early warning system. Bull Earthq Eng 1:157-163

Espinosa-Aranda JM, Jimenez A, Ibarrola G, Alcantar F, Aguilar A, Inostroza M, Maladonado S (1995) Mexico City seismic alert system. Seismol Res Lett 66:42-52

Espinosa-Aranda JM, Cuellar A, Garcia A, Ibarrola G, Islas R, Malolonado S, Rodriguez FH (2009) Evolution of the Mexico seismic alert system (SASMEX). Seismol Res Lett 80(5):694706 
Gilead W, Allen RM, Peter L (2007) Toward earthquake early warning in northern California. J Geophys Res 112:B08311

Hsiao NC, Wu YM, Shin TC, Zhao L, Teng TL (2009) Development of earthquake early warning system in Taiwan. Geophys Res Lett 36:L00B02

Iglesias A, Singh SK, Santoyo MA, Pacheco J, Ordaz M (2007) The seismic alert system for Mexico City: an evaluation of its performance and a strategy for its improvement. Bull Seismol Soc Am 97(5):1718-1729

Jin X, Zhang HC, Li J, Wei YX, Ma Q (2012) Research on earthquake early warning magnitude estimate. Acta Seismol Sin 34(5)

Kamigaichi O (2004) JMA earthquake early warning. J Jpn Assoc Earthq Eng 4(3):134-137

Kamigaichi O, Saito M, Doi K, Matsumori T, Tsukada S, Takeda K, Shimoyama T, Nakamura K, Kiyomoto M, Watanabe Y (2009) Earthquake early warning in Japan: warning the general public and future prospects. Seismol Res Lett 80(5):717-726

Li Y (2007) Elementary applications for a tentative earthquake warning system upon the planet earth (Test Version). Prog Geophys 22(4):1066-1069

Li Y (2008) Possibility to detect Wenchuan M8 earthguake by the Earthquake Warning System. Prog Geophys 23(3):969-971

Li SY, Ma Q, Jin X, Song JD (2004) Study on earthquake early warning system and intelligent emergency controlling system. World Earthq Eng 20(4):21-26

Liao X, Huang H (2002) Study on earthquake alarm system for enterprises. Earthq Eng Eng Vib 22(6):142-149

Ma Q (2008) Study an application on earthquake early warning. Institute of Engineering Mechanics, China Earthquake Administration, Harbin

Nakamura Y (1988) On the urgent earthquake detection and alarm system (UrEDAS). In: Proceedings of ninth world conference on earthquake engineering, vol 7, pp 673-678

Nakamura H, Horiuchi S, Wu CJ, Yamamoto S, Rydelek PA (2009) Evaluation of the real-time earthquake information system in Japan. Geophys Res Lett 36:L00B01

Ni SD (2008) Progress in real-time seismology. S\&T Disaster Relief 23(4):311-316
Olson EL, Allen RM (2005) The deterministic nature of earthquake rupture. Nature 438:212-215

Peng HS, Wu ZL, Wu YM, Yu SHM, Zhang DN, Huang WH (2011) Developing a prototype earthquake early warning system in the Beijing capital region. Seismol Res Lett 82(3):394-403

Suarez G, Novelo D, Mansilla E (2009) Performance evaluation of the seismic alert system (SAS) in Mexico City: a seismological and a social perspective. Seismol Res Lett 80(5):707-716

Wang WT, Ni SD, Chen Y, Kanamori H (2009) Magnitude estimation for early warning applications using the initial part of $\mathrm{P}$ waves: a case study on the 2008 Wenchuan sequence. Geophys Res Lett 36(16):L16305

Weber E, Convertito V, Iannaccone G, Zollo A, Bobbio A, Lantore L, Corciulo M, Crosta MD, Elia L, Martino C, Romeo A, Satriano C (2007) An advanced seismic network in the southern Apennines (Italy) for seismicity investigations and experimentation with earthquake early warning. Seismol Res Lett 78(6): 622-634

Wu YM, Kanamori H (2005) Experiment on an onsite early warning method for the Taiwan early warning system. Bull Seismol Soc Am 95(1):347-353

Wu YM, Teng TL (2002) A virtual subnetwork approach to earthquake early warning. Bull Seismol Soc Am 92(5):2008 2018

Wu YM, Shin TC, Chen CC, Tsai YB, Lee Willian HK, Teng TL (1997) Taiwan rapid earthquake information release system. Seismol Res Lett 68(6):931-943

Zhang HC, Jin X, Li J, Wei YX (2011) Research on earthquake early warning location methods. Earthq Eng Eng Vib 31(3)

Zhang HC, Jin X, Li J, Wei YX, Zhu HY (2013) Progress of research and application of earthquake early warning systems (EEWS). Prog Geophys 28(2):706-719

Zollo A, Convertito V, Iannaccone G, Manfredi G (2004) Development and experimentation of a prototype system for seismic early warning applications in Campania region (Southern Italy). In: Workshop on seismic early warning for European cities (abstracts), 23-25 September 2004, Napoli, Italy 